\title{
Knowledge of Tuberculosis and Influencing Factors among New Pulmonary Tuberculosis Patients in Yemen
}

\author{
Mohammed Saif Anaam ${ }^{1 *}$, Saud Alsahali ${ }^{1}$, Saeed O. Alfadly ${ }^{1,3}$, Mahfoudh Al-Musali², Khalid Siddeeg ${ }^{1}$, Adel H. \\ Aldhubhani ${ }^{4}$ \\ ${ }^{1}$ Department of Pharmacy Practice, Unaizah College of Pharmacy (UCP), Qassim University, KINGDOM OF SAUDI ARABIA. \\ ${ }^{2}$ Department of Pharmacology and Toxicology, Unaizah College of Pharmacy (UCP), Qassim University, KINGDOM OF SAUDI \\ ARABIA.
}

${ }^{3}$ Pharmacy Department, College of Medicine and Health Sciences, Hadramout University, YEMEN.

${ }^{4}$ Al-Rowaad Medical College, Sana'a, YEMEN.

Received: 23 October 2018;

Accepted: 01 December 2018

*Correspondence to:

Dr. Mohammed Saif Anaam,

Department of Pharmacy Practice, Unaizah College of Pharmacy (UCP), Qassim University, KINGDOM OF SAUDI ARABIA.

Email: drmsa.ucp1437@gmail.com

Copyright: (1) the author(s),publisher and licensee Indian Academy of Pharmacists. This is an open-access article distributed under the terms of the Creative Commons Attribution Non-Commercial License, which permits unrestricted non-commercial use, distribution, and reproduction in any medium, provided the original work is properly cited.

\begin{abstract}
Background: Tuberculosis (TB) remains a serious cause of illness in Yemen. Knowledge is believed to be associated with patients' willingness to seek treatment and adherence to treatment. Objectives: To assess patients' knowledge of TB and identify possible influencing factors. Methods: A cross-sectional study was conducted for a period of three months (October to December, 2013) to assess knowledge of TB among new TB patients in five Yemini regions. Descriptive results were presented as frequencies and percentage. Kolmogorov-Smirnov test (K-S test) was used for normality test. Chi-square $\left(\mathrm{X}^{2}\right)$ testing and Kruskal-Wallis $\mathrm{H}$ test were used to describe differences between groups. Multiple linear regression was performed to identify factors influencing the knowledge. Multicollinearity was considered before performing multiple linear regression. SPSS version 18 (Chicago, IL) was used for data analysis. Results: A total of 450 patients with a mean age $( \pm S D)$ of $32.7( \pm 13.6)$ years (range $15-80$ years) were interviewed; $59.3 \%$ of respondents were males, $64.4 \%$ of respondents reported receiving TB information from the health staff. Slightly more than half (55.6\%) of the patients' were aware about the method of TB transmission. The majority (82.2\%) of the respondents knew that TB is a curable disease. About two thirds (71.8\%) of the tuberculosis patients were found to be aware about duration of treatment. About $271(60.2 \%)$ of the respondents were categorized as having a good level of knowledge about TB. The median knowledge score was 4.0. Kruskal-Wallis $\mathrm{H}$ test showed significant differences in the medians between groups with regard to gender, age, education status, marital status, living status, stigma and receiving health education. However, multiple linear regression analysis showed that age, education status, stigma and receiving health education at health centers were the only factors that significantly influencing the knowledge. About $44 \%$ of the patients expressed fear of being known as tuberculosis patients in the community. Conclusion: The knowledge of TB and its treatment was generally moderate with a median score of 4 . Majority of the patients knew that TB is a curable disease with regular treatment and recommended duration. This will psychologically encourage them to adhere to treatment instructions.
\end{abstract}

Key words: Tuberculosis, Knowledge, Health education, Yemen.

\section{INTRODUCTION}

Tuberculosis is a contagious disease caused by an organism called Mycobacterium tuberculosis. These organisms are also known as Tubercle Bacilli. Strikingly, about one third of the world's population is infected with M. tuberculosis and at risk of developing the disease. In the meantime, more than eight million people develop active tuberculosis every year. In 2011, nine million cases of tuberculosis were reported globally which is equivalent to 131 cases per 100000 population. The mortality of this disease is as high as two million people every year worldwide. Among all of tuberculosis mortality cases reported globally, $98 \%$ of the death incidences are reported from developing countries which represented $25 \%$ of all avoidable deaths. About $95 \%$ of global TB cases occurred in developing countries, $75 \%$ of cases are in the most economically productive age group (15-50 years old). $\cdot^{[1-3]}$

According to the Yemen NTCP guideline, the latest estimated incidence of all forms of new TB cases was 14,400 with a rate of 60 per 100000 population.
The estimated incidence rate of new smear positive PTB was 25 per 100000 population with estimated 6,000 new smear positive cases in 2011. During 2011, a total of 3,135 new smear positive PTB cases were reported to NTCP with a notification rate of 15 per 100000 population. The case detection rate (CDR) was $76 \%$. All forms of notified TB cases were 8,636 TB cases. The CDR was $37 \%$. The estimated prevalence of all forms of TB cases is 70 per 100000 population with 17000 estimated prevalent cases. There were about $1400 \mathrm{~TB}$ deaths in 2011, with mortality rate of 6 per 100000 . A $73 \%$ of all notified new pulmonary smear positive cases are in the most productive age groups (15-49 years old). ${ }^{[4]}$ DOTS coverage reached $100 \%$ within Ministry of Health facilities in 2007. Treatment success rate increased from $50 \%$ before DOTS implementation to $86 \%$ for 2011 . Tuberculosis case notification is declined steadily from 2000, the question of whether this decrease is true epidemiological or related to operational factors is not solved yet. However, the last survey conducted in 2009, showed that the incidence of new smear positive PTB is 25 per 100000 population. ${ }^{[4]}$ 
In the literature, several different definitions of knowledge can be found. The Oxford English Dictionary (1999) defines knowledge as the "facts, feelings or experiences known by a person or a group of people". ${ }^{[5]}$ Knowledge gives a person the ability to use information to guide the actions of the person in a manner that is appropriate to the situation. Knowledge of any disease is necessary and important in order to optimize the patients' treatment and to improve their quality of life as well as to promote treatment adherence. ${ }^{[6]}$ Like other chronic illness, appropriate knowledge towards tuberculosis was significantly associated with positive healthcare seeking action. ${ }^{[7]}$ Lack of knowledge about the disease causes underutilization of the services, delay in seeking diagnosis and poor treatment adherence. ${ }^{[8]}$ Non-adherence to treatment often results from inadequate knowledge or understanding of the disease and its treatment. ${ }^{[9-14]}$ Literature indicates that TB control can significantly be enhanced if more concern is given to improve knowledge and attitudes towards disease. ${ }^{[15]}$

To the best of our knowledge and through extensive literature review, no studies have been reported from Yemen focusing on knowledge of TB and its treatment. Therefore; the present study was designed to assess the knowledge towards TB among new pulmonary tuberculosis patients in DOTS programme in Yemen.

\section{MATERIALS AND METHODS}

\section{Pretest}

To assess content validity the first draft of the questionnaire was presented to a panel of three local experts in questionnaire design. Face validity of the questionnaire was tested by administrating the questionnaire to 30 patients. Time taken to complete the questionnaire, difficulties in patient comprehension and the extent of patient acceptance were recorded. The questionnaire was administrated to the same patients for reliability test. Cronbach's alpha test of internal consistency was 0.79 for the six items used to assess the patients' knowledge on tuberculosis.

\section{Study design}

A cross-sectional study was conducted for a period of three months (October to December, 2013) to assess knowledge on TB and its treatment among new TB patients as well as to identify possible influencing factors on the patients' knowledge. The pre-tested questionnaire which included information about socio-demographic characteristics and knowledge about TB and its treatment was used. A total TB knowledge score was created by summing the scores for six questions. The score ranged from 0 to 6 , with the higher the score, the greater the patient's TB knowledge. Patients' knowledge about TB was established based on the replies provided to the given questions by the patients throughout the interview.

\section{Study area and population}

The study was conducted at health centers where TB units exist throughout the 5 regions of Yemen. The study population was a cohort of pulmonary tuberculosis (PTB) patients registered for DOTS in each TB unit. The target population of the study was all positive TB patients receiving treatment under DOTS during the study period.

\section{Data collection}

The data were collected by face-to-face interviews using a pilot test questionnaire after obtaining informed consent from the participants. The questionnaire consisted of two sections. Section one dealt with patient background characteristics (sex, age, residence, educational status, marital status, living status, stigma and education received in the health centre. Meanwhile, the section two estimated patients' knowledge of tuberculosis through six basic questions. To avoid interviewer bias, the interviewers were not associated with the TB control health services. Interviews with participants took place in a private room at the target health centre to avoid response bias. All interviews were conducted by interviewers who were separately trained for this purpose.

\section{Ethical issues and confidentiality}

The research was approved by the Ethics Committee of Medical Research in the Ministry of Public Health and Population. Verbal consent was obtained from the patients.

\section{Statistical analysis}

Descriptive results were presented as frequencies and percentage. Kolmogorov-Smirnov test (K-S test) was used for normality test. Chi-square $\left(X^{2}\right)$ testing and Kruskal-Wallis $H$ test was used to describe median differences between groups. Multiple linear regression was performed to identify factors influencing the knowledge score. Multicollinearity was considered before performing multiple linear regression. To test reliability, the internal consistency was assessed using Cronbach's alpha. The criterion for accepting Cronbach's alpha was a score above 0.7 (Bland and Altman, 1997). Epi Data software (Version 3.1) was used to validate data entry. Valid data were exported to SPSS version 18 (Chicago, IL) for further analysis. Statistical significance set at $P<0.05$.

\section{RESULTS}

The general characteristics of the patients are summarized in Table 1. Of the 450 patients interviewed, $297(59.3 \%)$ were males. Age ranged from 15 to 80 years (mean 32.7 years, SD 13.6). Approximately $90 \%$ of the respondents were at their most economically productive age (15-54 years). About 35\% of the patients were illiterates. Majority of the patients $440(97.8 \%)$ were living with family or friends. About $64 \%$ of the study respondents reported receiving health education by the health staff. One hundred ninety six (43.6\%) of the patients, expressed fear of being known as tuberculosis patients in the community.

\section{Patients' Knowledge of Tuberculosis}

Slightly more than a half of respondents $(55.6 \%)$ knew that TB is a transmitted through airborne droplet nuclei. Only 150 (33.3) reported that TB patients should not eat together with family. About $61 \%$ of the patients were aware that the family members need to be screened for tuberculosis. Majority of the patients $(82.2 \%)$ reported that TB is a curable disease. When the study participants were asked about the curability of the disease with 4-week course, $72 \%$ of the respondents reported that TB cannot be cured. But when they were asked about the duration of TB treatment, only $59.3 \%$ reported that the treatment can't be stopped once they were symptoms free and the treatment duration must be reached. Based on the response to the questions, $271(60.2 \%)$ of the respondents were categorized as having good level of knowledge about TB. Table 2 showed the responses to TB knowledge questions among TB patients.

The median knowledge score among study participants was $4.0(I Q R=3.0-5.0)$. Kruskal-Wallis $\mathrm{H}$ test showed significant differences in the medians between groups and were as follow gender $[H(1)=4.4, p=0.04]$, age $[H(4)=26.2$, $p<0.001]$, education status $[H(1)=65.8, p<0.001]$, marital status $[H(3)=16.5$, $p=0.001]$, living status $[H(1)=4.3, p=0.04]$, stigma $[H(1)=27.7, p<0.001]$ and receiving health education $[H(1)=18.9, p<0.001]$. Table 3 summarized the 


\begin{tabular}{|c|c|}
\hline Variable & n (\%) \\
\hline \multicolumn{2}{|l|}{ Gender } \\
\hline Male & $267(59.3)$ \\
\hline Female & $183(40.7)$ \\
\hline \multicolumn{2}{|l|}{ Age } \\
\hline $15-24$ & $158(35.1)$ \\
\hline $25-34$ & $115(25.6)$ \\
\hline $35-44$ & $93(20.7)$ \\
\hline $45-54$ & $39(8.7)$ \\
\hline 55 and more & $45(10.0)$ \\
\hline \multicolumn{2}{|l|}{ Region } \\
\hline North & $45(10.0)$ \\
\hline East & $45(10.0)$ \\
\hline Middle & $68(15.0)$ \\
\hline West & $112(25.0)$ \\
\hline South & $180(40.0)$ \\
\hline \multicolumn{2}{|l|}{ Education Status } \\
\hline Educated & $293(65.1)$ \\
\hline Illiterate & $157(34.9)$ \\
\hline \multicolumn{2}{|l|}{ Marital Status } \\
\hline Single & $166(36.9)$ \\
\hline Married & $265(58.9)$ \\
\hline Divorced & $6(1.3)$ \\
\hline Widowed & $13(2.9)$ \\
\hline \multicolumn{2}{|l|}{ Living Status } \\
\hline With family/friends & $440(97.8)$ \\
\hline Alone & $10(2.2)$ \\
\hline \multicolumn{2}{|l|}{ Stigma } \\
\hline Yes & $231(51.3)$ \\
\hline No & $219(48.7)$ \\
\hline \multicolumn{2}{|l|}{ Health Education } \\
\hline Yes & $290(64.4)$ \\
\hline No & $160(35.6)$ \\
\hline
\end{tabular}

\section{Table 2: Responses to TB knowledge questions among 450 TB patients.}

\begin{tabular}{|l|l|}
\hline Response to questions & $\boldsymbol{n}(\%)$ \\
\hline How is tuberculosis transmitted? & \\
\hline Droplet & $250(55.6)$ \\
\hline Eating utensils & $154(34.2)$ \\
\hline Don't know & $46(10.2)$ \\
\hline Would you eat together with family? & \\
\hline Yes & $272(60.4)$ \\
\hline No & $150(33.3)$ \\
\hline Unsure & $28(6.2)$ \\
\hline Do family members need to be screened for tuberculosis? & \\
\hline Yes & $275(61.1)$ \\
\hline No & $106(23.6)$ \\
\hline Unsure & $69(15.3)$ \\
\hline Is tuberculosis curable with proper treatment? & \\
\hline Yes & $370(82.2)$ \\
\hline No & $43(9.6)$ \\
\hline Unsure & $37(8.2)$ \\
\hline Can tuberculosis be cured with a 4-week course? & $323(71.8)$ \\
\hline Yes & $46(10.2)$ \\
\hline No & \\
\hline Unsure & $267(59.3)$ \\
\hline Can treatment be stopped once you are symptom free even \\
\hline Yes & $143(31.8)$ \\
\hline No & \\
\hline Unsure & \\
\hline
\end{tabular}

of TB, $55.6 \%$ of the respondents in the current study declared that TB is transmitted by droplets, these findings are consistent with earlier studies reported in literature. ${ }^{[17-22]}$ However, contrary to our findings, respondents from other studies ${ }^{[23-27]}$ reported poor knowledge about the transmission of TB. When the study participants were asked about eating together with family, $60 \%$ of respondents have a positive response; these findings were not in agreement with Malaysian study ${ }^{[23]}$ where only $40 \%$ of respondents have positive response. Regarding the family members if they need to be screened for tuberculosis, about $61 \%$ have a positive response towards a necessity of screening, this was consistent with Malaysian study. ${ }^{[23]}$

Most of the respondents were aware that TB is a highly infectious but curable disease. Majority of the patients $(82.2 \%)$ in our study reported that TB is a curable disease; these findings are consistent with earlier studies reported in literature. ${ }^{[16-17,20-21,23-24,27]}$ When the study participants were asked about the curability of the disease with 4 -week course, $72 \%$ of the respondents reported that TB cannot be cured; these findings are consistent with earlier studies reported in literature..$^{[16,20,23]}$ On the other hand, when the patients were asked about the duration and a possibility of stopping treatment once they were symptoms free, $71.8 \%$ reported that the treatment cannot be stopped within 4 weeks or once the patient was symptoms free and the treatment duration must be reached. This finding was supported by other studies. ${ }^{[17,19,20-21,23]}$ However, these finding were not in line with other studies reported in literature. ${ }^{[24,27,28]}$

Our study findings showed a significant difference in median scores for gender, age, education, marital, living status, stigma and health education. 


\begin{tabular}{|c|c|c|c|c|}
\hline $\begin{array}{l}\text { Patient's } \\
\text { characteristic }\end{array}$ & $\begin{array}{l}\text { Interviewed } \\
\text { n (\%) }\end{array}$ & $\begin{array}{l}\text { Knowledge } \\
\text { score } \\
\text { Mean rank }\end{array}$ & $\begin{array}{l}\text { Chi- } \\
\text { Square }\end{array}$ & $\begin{array}{l}P \\
\text { value* }\end{array}$ \\
\hline $\begin{array}{l}\text { Gender } \\
\text { Male } \\
\text { Female }\end{array}$ & $\begin{array}{l}276(59.3) \\
183(40.7)\end{array}$ & $\begin{array}{l}236.0 \\
210.2\end{array}$ & 4.4 & 0.04 \\
\hline $\begin{array}{l}\text { Age group } \\
15-24 \\
25-34 \\
35-44 \\
45-54 \\
55-\text { and more }\end{array}$ & $\begin{array}{l}158(35.1) \\
115(25.6) \\
93(20.7) \\
39(8.7) \\
45(10.0)\end{array}$ & $\begin{array}{l}248.9 \\
249.0 \\
204.1 \\
178.4 \\
168.5\end{array}$ & 26.2 & $<0.001$ \\
\hline $\begin{array}{l}\text { Education Status } \\
\text { Educated } \\
\text { Illiterate }\end{array}$ & $\begin{array}{l}293(65.1) \\
157(34.9)\end{array}$ & $\begin{array}{l}261.2 \\
158.9\end{array}$ & 65.8 & $<0.001$ \\
\hline $\begin{array}{l}\text { Marital Status } \\
\text { Single } \\
\text { Married } \\
\text { Divorced } \\
\text { Widowed }\end{array}$ & $\begin{array}{l}166(36.9) \\
265(58.9) \\
6(1.3) \\
13(2.9)\end{array}$ & $\begin{array}{l}249.6 \\
216.0 \\
209.9 \\
119.0\end{array}$ & 16.5 & 0.001 \\
\hline $\begin{array}{l}\text { Living Status } \\
\text { With family/friend } \\
\text { Alone }\end{array}$ & $\begin{array}{l}440(97.8) \\
10(2.2)\end{array}$ & $\begin{array}{l}227.4 \\
143.2\end{array}$ & 4.3 & 0.04 \\
\hline $\begin{array}{l}\text { Stigma } \\
\text { Yes } \\
\text { No }\end{array}$ & $\begin{array}{l}219(48.7) \\
231(51.3)\end{array}$ & $\begin{array}{l}258.0 \\
194.7\end{array}$ & 27.7 & $<0.001$ \\
\hline $\begin{array}{l}\text { Health Education } \\
\text { Yes } \\
\text { No }\end{array}$ & $\begin{array}{l}290(64.4) \\
160(35.6)\end{array}$ & $\begin{array}{l}244.9 \\
190.4\end{array}$ & 18.9 & $<0.001$ \\
\hline
\end{tabular}

$P$ value* is based on a comparison of two or several medians using Kruskal-Wallis $\mathrm{H}$ test.

From the current study, educated respondents had better Knowledge of TB. Several other studies ${ }^{[7,17,19,29-31]}$ also showed similar relationship between level of education and TB knowledge. Findings from current study also revealed that patients' knowledge is associated with gender and age, these findings are in line with some studies. ${ }^{[19,30-32]}$ However, contrary to our findings, other studies ${ }^{[17,29]}$ reported no association between patients' knowledge of TB and mentioned demographic factors (age and gender).

It was surprising to find that majority of the patients in south region (the highest educated region throughout the country) and those who had received health education in TB centers had knowledge scores below the overall median. However, this could be attributed to the political situation in the country and ongoing civil war.

\section{CONCLUSION}

The knowledge of TB and its treatment was generally moderate; it was strongly associated with level of education followed by age and place of residence however not by health education. Therefore, the health education that is giving to patients should be improved. Patients with limited access to media and low education levels may benefit from specially targeted educational interventions. To reduce stigma and the impact of social consequences of TB, an ongoing health education programme designed to increase the knowledge level in the whole population is recommended.

\section{ACKNOWLEDGEMENT}

None.

\section{CONFLICT OF INTEREST}

The authors declare no conflict of interest.

\section{AUTHORS' CONTRIBUTIONS}

The authors declare that this work was done by the authors named in this article and all liabilities pertaining to claims relating to the content of this article will be borne by them.

MSA contributed to the design of the study, coordinated the inclusion and data acquisition, acquired and analyzed data and wrote the article, was responsible for the conduct of the study.

SA, SOA, MA, KS contributed to the conception of the study and design and have been involved in revising the article critically for important intellectual content. AHA contributed to the acquisition of data and coordinated for the study.

All authors read and approved the final version of the manuscript.

\section{ABBREVIATIONS}

TB: Tuberculosis; PTB: Pulmonary tuberculosis; NTCP: National TB control programme; CDR: Case detection rate; DOTs: Directly Observed Treatment, Short-course; IQR: Interquartile range; WHO: World Health Organization.

\section{REFERENCES}

1. WHO. Management of tuberculosis: Training for health facility staff. WHO/CDS/ TB/2003.314a, Geneva, WHO. 2003a.

2. WHO. Treatment of tuberculosis: Guidelines for national programmes, third edition). WHO/CDS/TB/2003.313, Geneva, WHO. 2003

3. WHO. Global tuberculosis programme. Global tuberculosis control: WHO Report 2010. WHO/HTM/TB/2010.126. Geneva, Switzerland: WHO. 2010.

4. National Tuberculosis Control Programme. Tuberculosis Control Programme Manual, second edition, Sana'a, Ministry of Public Health and Population of Yemen. 2010.

5. Bernus P, Fox M. Knowledge sharing in the integrated enterprise: interoperability strategies for the enterprise architect. Springer Science and Business Media. 2005;20.

6. Jaramillo $\mathrm{E}$. The impact of media-based health education on tuberculosis diagnosis in Cali, Colombia. Health Policy and Planning. 2001;16(1):68-73.

7. Hoa NP, Thorson AE, Long NH, Diwan VK. Knowledge of tuberculosis and associated health-seeking behaviour among rural Vietnamese adults with a cough for at least three weeks. Scandinavian Journal of Public Health. 2003;31(62 Suppl):59-65.

8. Stop TB Partnership and the World Health Organization. The Global Plan to Stop Tuberculosis, 2006-2015. WHO/HTM/ STB/2006.35. Geneva, Switzerland: WHO. 2006.

9. Sockrider MM, Wolle JM. Helping patients better adhere to treatment regimens. Journal of Respiratory Diseases. 1996;17:204-34.

10. Anaam MS, Ibrahim M, Izham M, Serouri A, Wahed A, Aldobhani A. Factors affecting patients' compliance to anti-tuberculosis treatment in Yemen. Journal of Pharmaceutical Health Services Research. 2013;4(2):115-22.

11. Dworkin MS, et al. Factors that complicate the treatment of tuberculosis in HIV-infected patients. J Acquir Immune Defic Syndr. 2005;39(4):464-70.

12. Vijay $\mathrm{S}$, et al. Risk factors associated with default among new smear positive TB patients treated under DOTS in India. PLoS One. 2010;5(4):e10043.

13. Lúcia MP, Eliane DG. Profile of notified tuberculosis cases and factors associated with treatment dropout. Rev Saude Publica. 2007;41(2):205-13.

14. Tekle B, et al. Defaulting from DOTS and its determinants in three districts of Arsi Zone in Ethiopia. Int J Tuberc Lung Dis. 2002;6(7):573-9.

15. Alvarez-Gordillo GD, Alvarez-Gordillo JF, Dorantes-Jiménez JE, Halperin-Frisch D. Perceptions and practices of tuberculosis patients and non-adherence to therapy in Chiapas, Mexico. Salud Publica deMexico. 2000;42(6):520-8. 


\section{Anaam, et al.: Patient's Knowledge About Tuberculosis}

16. Tesfahuneygn G. Knowledge and Practice of TB Patients on TB and its Treatment in Alamata District Tigray Region Northeast Ethiopia. Mycobact Dis. 2017;7:240. doi:10.4172/2161-1068.1000240.

17. Wandwalo ER, Mørkve O. Knowledge of disease and treatment among tuberculosis patients in Mwanza, Tanzania. The International Journal of Tuberculosis and Lung Disease. 2000;4(11):1041-6

18. Tasnim S, Rahman A, Hoque FM. Patient's knowledge and attitude towards tuberculosis in an urban setting. Pulmonary Medicine. 2012;2012.

19. Mondal MNI, Nazrul HM, Chowdhury MRK, Howard J. Socio-demographic factors affecting knowledge level of Tuberculosis patients in Rajshahi City, Bangladesh. African Health Sciences. 2014;14(4):855-65.

20. Das R, Baidya S. A Study on Knowledge of Pulmonary Tuberculosis and DOTS among Pulmonary Tuberculosis Patients in West Tripura District, India. SAARC Journal of Tuberculosis, Lung Diseases and HIVIAIDS. 2016;12(1):1-7.

21. Paramasivam S, Thomas B, Thayyil J, Rahim A, Thavody J, Lilabi MP et al. Knowledge and health seeking behaviour of tuberculosis patients in Kerala, India. International Journal of Community Medicine and Public Health. 2016;3(9):2464-71.

22. Eram U, Nawab T, Khalique N. Patients Knowledge and Attitude towards Tuberculosis in a Rural Setting in Aligarh. International Journal of Pharmaceutical Science Invention (Online). 2016;5(71):31-4.

23. Liam CK, Lim KH, Wong CMM, Tang BG. Attitudes and knowledge of newly diagnosed tuberculosis patients regarding the disease and factors affecting treatment compliance. The International Journal of Tuberculosis and Lung Disease. 1999;3(4):300-9.

24. Mohamed Al, Yousif MA, Ottoa P, Bayoumi A. Knowledge of tuberculosis: a survey among tuberculosis patients in Omdurman, Sudan. Sudanese Journal of Public Health. 2007;2(1):22.
25. Anjum A, Daud S, Mukhtar F. Tuberculosis: awareness about spread and control. Professional Med J. 2009;16(1):61-6.

26. Tachfouti N, Slama K, Berraho M, Nejjari C. The impact of knowledge and attitudes on adherence to tuberculosis treatment: a case-control study in a Moroccan region. Pan African Medical Journal. 2012;12(1).

27. Khalil S, Ahmad E, Khan Z, Perwin N. A study of knowledge and awareness regarding pulmonary tuberculosis in patients under treatment for tuberculosis in a rural area of Aligarh - UP. Indian J Community Health. 2011;23(2):93-5.

28. Khan JA, Irfan M, Zaki A, Beg M, Hussain SF, Rizvi N. Knowledge, attitude and misconceptions regarding tuberculosis in Pakistani patients. Journal of Pakistan Medical Association. 2006;56(5):211.

29. Hossain S, Zaman K, Quaiyum A, Banu S, Husain A, Islam A, et al. Factors associated with poor knowledge among adults on tuberculosis in Bangladesh: results from a nationwide survey. Journal of Health, Population and Nutrition. 2015;34(1):2.

30. Sreeramareddy CT, Kumar HH, Arokiasamy JT. Prevalence of self-reported tuberculosis, knowledge about tuberculosis transmission and its determinants among adults in India: results from a nation-wide cross-sectional household survey. BMC Infectious Diseases. 2013;13(1):16

31. Hoa NP, Diwan VK, Co NV, Thorson AEK. Knowledge about tuberculosis and its treatment among new pulmonary TB patients in the north and central regions of Vietnam. The International Journal of Tuberculosis and Lung Disease. 2004;8(5):603-8.

32. Gelaw SM. Socioeconomic factors associated with knowledge on tuberculosis among adults in Ethiopia. Tuberculosis Research and Treatment. 2016;2016.

Cite this article as: Anaam MS, Alsahali S, Alfadly SO, Al-Musali M, Siddeeg K, Aldhubhani AH. Knowledge of Tuberculosis and Influencing Factors among New Pulmonary Tuberculosis Patients in Yemen. J Pharm Pract Community Med. 2018;4(4):197-201. 